\title{
EVAMAPPER: A NOVEL MATLAB TOOLBOX FOR EVAPOTRANSPIRATION MAPPING
}

\author{
U. H. Atasever ${ }^{\text {a }}$ M. H. Kesikoğlu', C. Özkan ${ }^{\mathrm{a}}$ \\ ${ }^{a}$ Dept. of Geomatic Engineering, Erciyes University, Kayseri, Turkey- \\ (uhatasever, hayrikesikoglu,cozkan)@erciyes.edu.tr
}

Commission VII, WG VII/1

KEY WORDS: SEBAL, EvaMapper, Evapotranspiration (ET) Mapping

\begin{abstract}
:
Water consumption has been exceeding as the world population increases. Therefore, it is very important to manage water resources with care as it is not an endless resource. The Water loss in regional scale is the key phenomena to accomplish this goal. One of the main components of this phenomenon is evapotraspiration (ET) due to being one of the most important parameter for the management of water resources. Until recent years, evapotranspiration calculations were performed locally, using data obtained from weather stations. But for a successful water management, regional evapotranspiration maps are required. Different approaches are used to compute regional ETs. Among them, the direct measurement methods are not cost-effective and regionalized. For costeffective and regional ET mapping, Surface Energy Balance Algorithm (SEBAL) is the most known and effective technique. In this study, EvaMapper Toolbox which is based on SEBAL approach are developed for regional evapotranspiration mapping in MATLAB. By this toolbox, researchers can apply SEBAL technique which has a very complex structure to their study area easily through entering regional parameter values.
\end{abstract}

\section{Introduction}

For effective using of water and water resources whose importance has been increased over the past years, it is very fundamental to be sustainable for water resources. For this purpose, it is necessary to identify the basin budget items. The very beginning of basin budget items is evapotranspiration. Evapotranspiration has a very important place in identifying project, operating and directing of irrigation systems, also in hydrological works, especially in reservoir operating works. Because, ET directly plays a role in calculating the water need of plant. It is necessary to measure ET correctly in irrigated agriculture as it is a very important parameter for evaluating the effects of changes of land use in wetlands, irrigation method, optimizing the growth of plant (Singh, 2008). Although there are a lot of point source calculation methods such as Penman, Hargreaves to calculate ET, regional ET values are necessary for planning. SEBAL is an image processing algorithm that can produce ET maps by using remote sensing technology. In this model, ET values are calculated pixel by pixel (Bastiaanssen, 1998a).

\section{Surface Energy Balance Algorithm (SEBAL)}

SEBAL is an approach developed by Bastiansen for producing actual ET maps belonging to wide areas by using satellite images (Bastiaanssen, 1998a; Bastiaanssen 1998b). In this approach, there is no need any information related to any kind of soil or crop and land use. In the SEBAL technique, energy balance should be applied for every pixel of satellite image. The basic energy balance is defined as:

$$
L E=R_{n e t}-H-G
$$

In this equation, $L E$ is latent heat flux to be transformed ET value, $R_{n e t}$ is net radiation, $H$ is sensible heat flux and lastly $G$ is soil heat flux. In brief, In SEBAL, components of energy balance is calculated then subtracted the components and lastly computed the latent heat flux to be transformed to ET value.

\subsection{Net Radiation $\left(\boldsymbol{R}_{\text {net }}\right)$}

Net radiation is calculated by subtracting outgoing radiation from incoming radiation. Net radiation is positive along the day and negative at nights. Net radiation can be expressed as

$$
R_{\text {net }}=R_{S} \downarrow-R_{S} \uparrow+R_{L} \downarrow-R_{L} \uparrow-\left(1-\varepsilon_{\text {sur }}\right) R_{L} \downarrow
$$

In equation, $R_{S} \downarrow$ is incoming shortwave radiation (W $\mathrm{m}^{-2}$ ); $R_{S} \uparrow$ is outgoing shortwave radiation (W $\mathrm{m}^{-2}$ ); $\quad R_{L} \downarrow$ is incoming longwave radiation ( $\mathrm{m}^{-2}$ ); $\quad R_{L} \uparrow$ is outgoing longwave radiation $\left(\mathrm{W} \mathrm{m}^{-2}\right)$ and $\varepsilon_{\text {sur }}$ is surface emissivity.

Surface emissivity $\left(\varepsilon_{\text {sur }}\right)$ is calculated using NDVI and empirically derived equation from (Van De Griend,1993; Bastiaanssen, 1998a).

\subsection{Soil Heat Flux (G)}

Soil heat flux can be defined as the rate of heat storage in the soil and vegetation through conduction (Allen, 2007). Bastiaanssen has suggested an experimental equation that can be used in agricultural areas for calculation of soil heat flux (Bastiaanssen, 2000). This equation is:

$$
G=R_{\text {net }} \frac{T_{\text {sur }}}{\alpha}\left(0.0038 \alpha+0.0074 \alpha^{2}\right)\left(1-0.98 N D V I^{4}\right)\left(W / m^{2}\right)
$$


In this equation, $T_{\text {sur }}$ is surface temperature $\left({ }^{\circ} \mathrm{C}\right)$ calculated from Landsat $6^{\text {th }}$ Band, $\alpha$ is surface albedo, NDVI is NDVI value belonging to every pixel.

\subsection{Sensible Heat Flux}

Sensible heat flux is the general name of transfer of heat energy derived from the temperature differences between surface and air. In calculating sensible heat flux, aerodynamic resistance is one of the steps of operation so it is quite complex. Sensible heat flux is calculated as (Singh, 2008):

$$
H=\rho_{a} * C_{p} * \frac{T_{0}-T_{a}}{r_{a h}}
$$

In this formula, $\rho_{a}$ is air density $\left(\mathrm{W} \mathrm{m}^{-2}\right), C_{p}$ is heat capacity of air $\left(\mathrm{J} \mathrm{Kg}^{-1} \mathrm{~K}^{-1}\right), T_{0}$ is air temperature in first reference height, $T_{a}$ is air temperature in second reference, $r_{a h}$ is aerodynamic resistance to heat transfer. $r_{a h}$ value is calculated with MoninObukhov Theory. Data such as wind speed and heat differences are attended in this step. Also, height corrections for every pixel are performed in this stage. Many sub-operations are necessary for $r_{a h}$ calculation. In this step, many parameters such as leaf area index (LAI), soil adjusted vegetation index (SAVI) and wind speed are used (Singh, 2008).

\subsection{Calculation of Daily Actual Evapotranspiration}

After calculating the instantaneous net radiation, soil heat flux and sensible heat flux, instantaneous latent heat flux (LE) is calculated by using equation 1. Later, evaporative fraction directly related to soil humidity conditions is calculated as (Bastiaanssen, 1998a):

$$
\Lambda=\frac{L E}{R_{n e t}-G}
$$

At last, daily actual ET is calculated as:

$$
E T_{a c t}=\frac{86400 \cdot \Lambda \cdot\left(R_{n e t 24}-G_{24}\right)}{\lambda \cdot \rho_{w}}
$$

where $R_{\text {net } 24}=$ daily net radiation $\left(\mathrm{Wm}^{-2}\right) ; G_{24}=$ daily soil heat flux $\left(\mathrm{Wm}^{-2}\right) ; \rho_{w}=$ density of water $\left(\mathrm{kg} \mathrm{m}^{-3}\right)$ and $\lambda=$ latent heat of vaporization $\left(\mathrm{J} \mathrm{kg}^{-1}\right)$

\section{EvaMapper Toolbox}

Matlab is a technical language developed for programming and high-level numerical calculation. Researchers can analyse the data and develop new algorithms by using Matlab. Programming process can be completed in a shorter time with the help of existing functions that will be able to use in many engineering problems. Due to the advantages like that, many researchers who works in remote sensing prefer Matlab.

In this action, SEBAL technique, one of the most used techniques for mapping evapotranspiration, is prepared as toolbox and forming an user interface makes the using of technique easier. By using this toolbox, the actual ET mapping of study area can be produced easily by entering necessary data and parameters (Landsat 5 Image, Meteorological Data, etc.) Graphic User Interface of toolbox is presented in Figure 1. Input parameters of EvaMapper Toolbox are

- Landsat TM Image

- Date of Image

- Average Temperature

- Location of Study Area

- $\quad$ Average Wind Speed

- Delta T Parameters (a and b)

EvaMapper Toolbox has many show options. findings such as NDVI map, SAVI Map, Emissivity Map and Surface Temperature Map can be investigated in addition to 24 Hour ET Map by using these options, Also, EvaMapper can be used easily by the researchers who cannot use Matlab with Windows Standalone application version compiled by using Matlab Compiler.

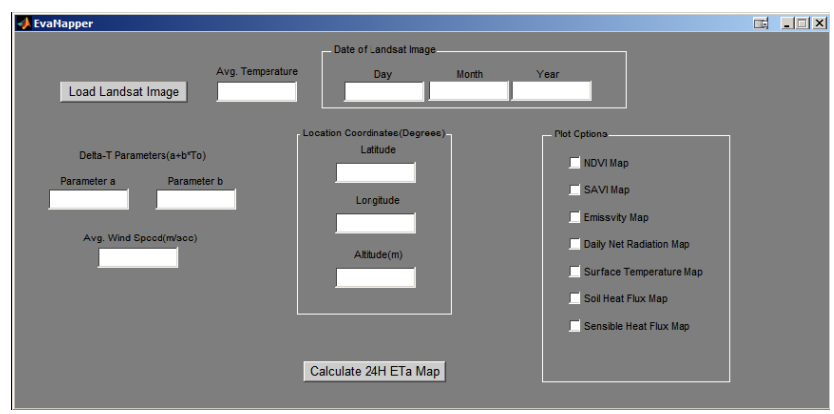

Figure 1. Graphic User Interface (GUI) of EvaMapper Toolbox

\section{Sample Application Using EvaMapper Toolbox}

An application has been performed by using EvaMapper toolbox prepared in the scope of this study. The selected study area is South of Adana which is one of the most important agriculture areas of Turkey. People can harvest three or four times in a year in Adana because of it is a very fertile region. So, it is very important to determine actual evapotranspiration. The study area is shown in Figure 2.

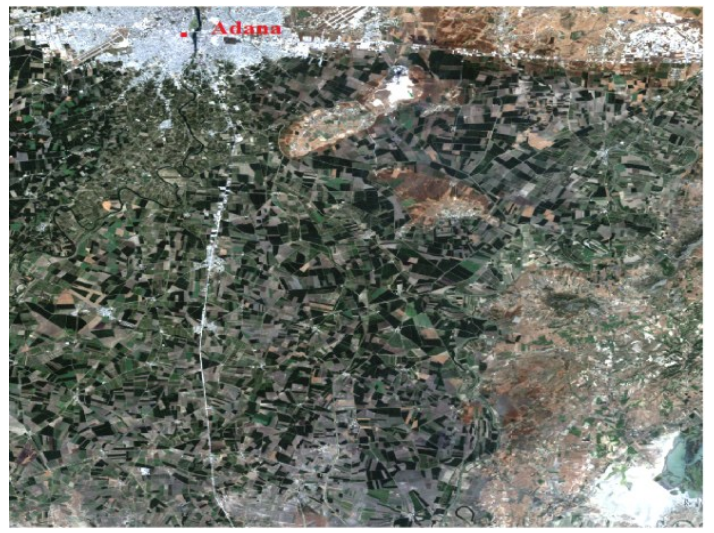

Figure 2. Study Area (South of Adana)

Instantaneous net radiation map is shown in Figure 3, NDVI map is in Figure 4, surface temperature map is in Figure 5, soil heat flux map is in Figure 6, sensible heat flux map is in Figure 7 , as a last, daily actual evapotranspiration map is in Figure 8 which are generated by EvaMapper Toolbox. 


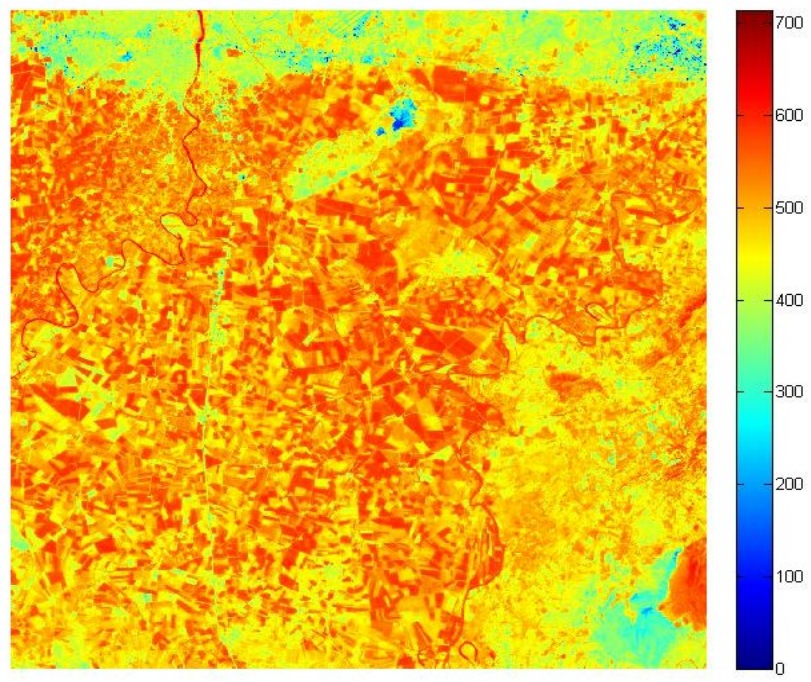

Figure 3. Instantaneous Net Radiation Map (W/m²)

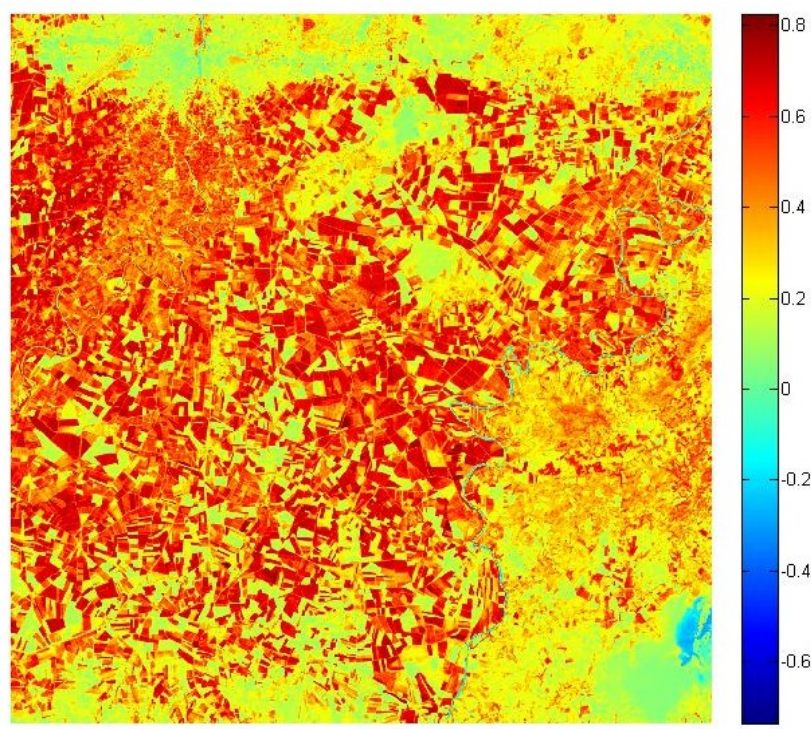

Figure 4. NDVI Map

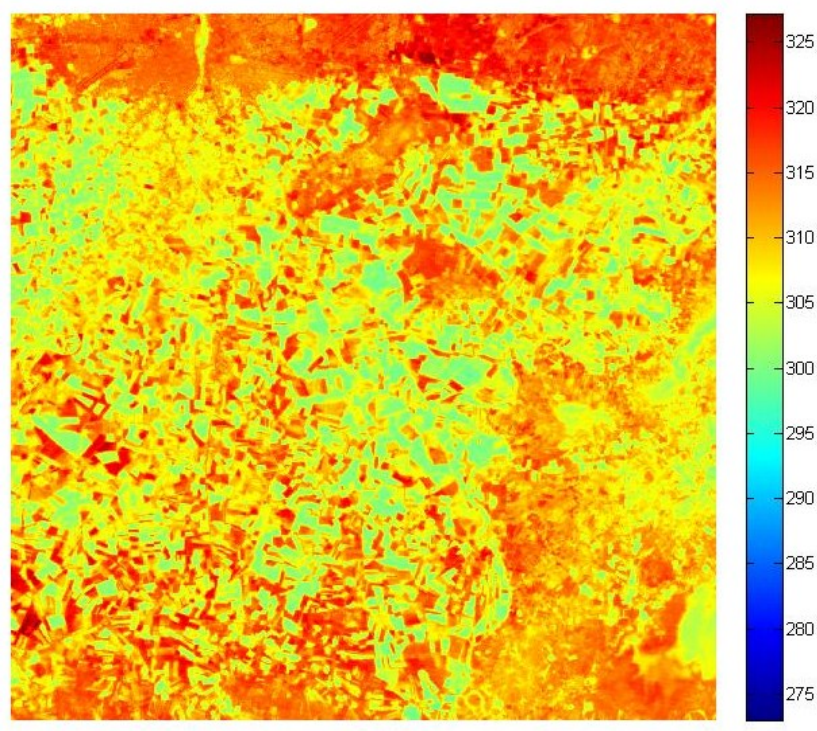

Figure 5. Surface Temperature Map (Kelvin)

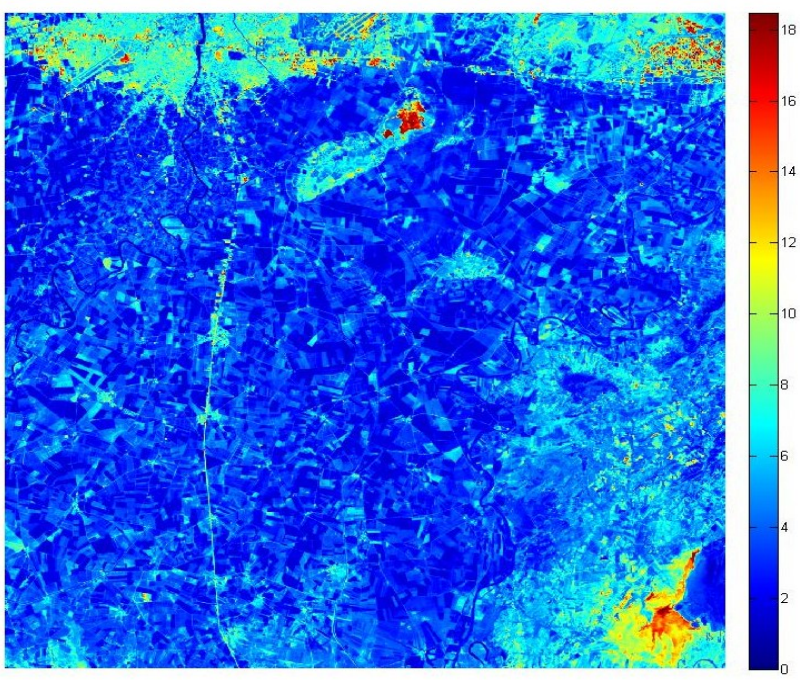

Figure 6. Soil Heat Flux Map (W/m²)

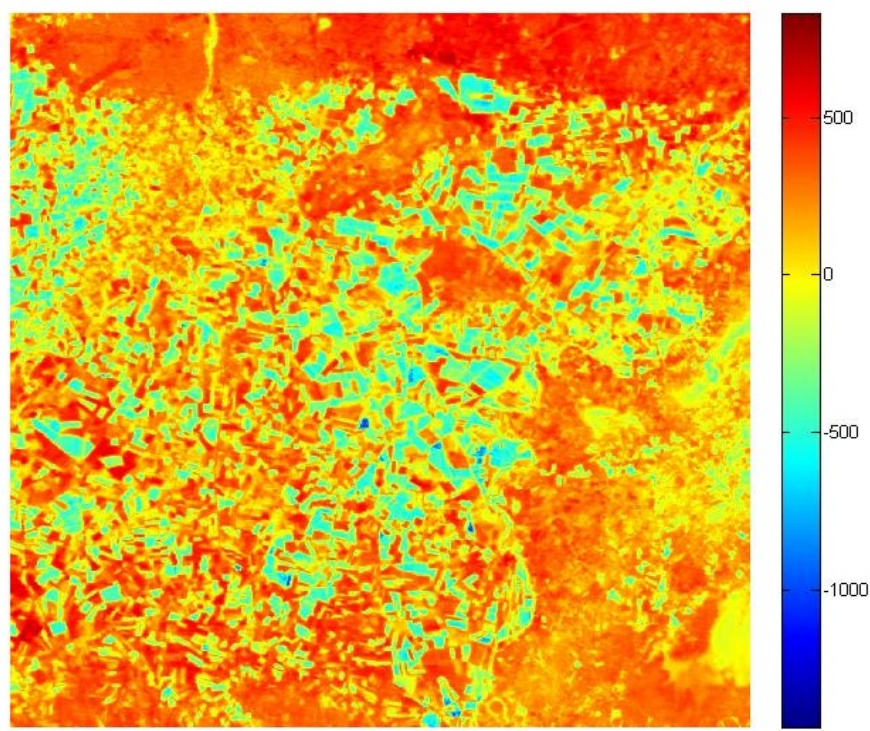

Figure 7. Sensible Heat Flux Map (W/m²)

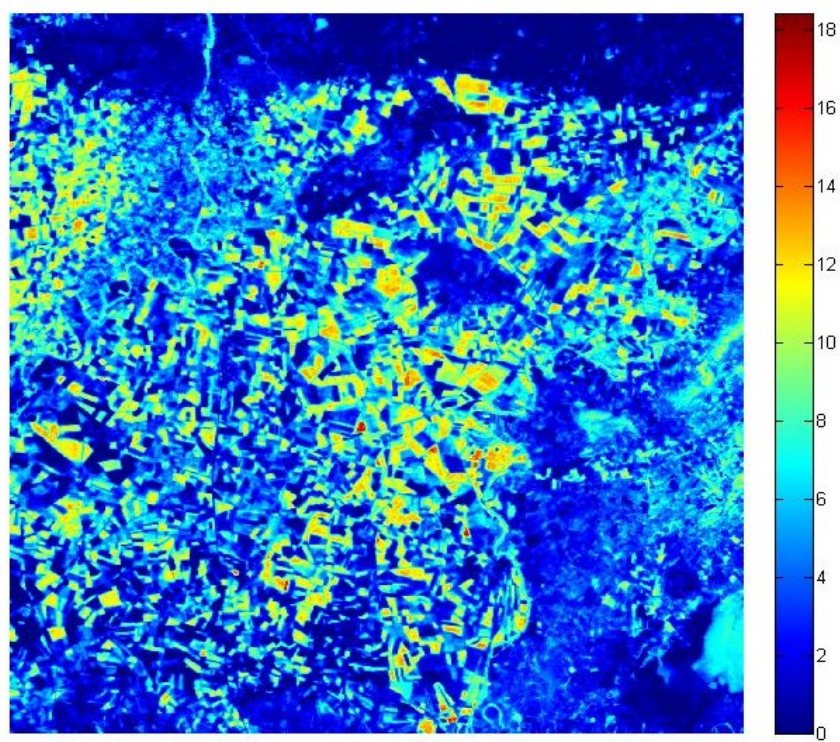

Figure 8. Daily Actual Evapotranspiration Map (mm/day) 


\section{Conclusions}

It is very difficult to calculate the real evapotranspiration in basin-based with direct measurement methods. But actual evapotranspiration can be calculated by using remote sensing technologies. Remote sensing is a kind of science that can give regular and objective information about study area. So, it is basic source of information of many environmental and agricultural applications belonging to wide areas. SEBAL is one of the most important techniques using science of remote sensing in producing real evapotranspiration maps. Many scientist and researchers who works in public institutions can easily generate actual ET maps by using EvaMapper Toolbox. In this study, a toolbox named EvaMapper that is SEBAL technique-based and an application has been performed as a sample.

\section{References}

Allen, R. G., Tasumi M., and Trezza R, 2007. Satellite-Based Energy Balance for Mapping Evapotranspiration With Internalized Calibration (METRIC) - Model, Journal of Irrigation and Drainage Engineering, 133(4), 380-394.

Bastiaanssen, W. G. M., Menenti, M., Feddes, R. A. and Holtslag, A. A. M., 1998. A remote sensing surface energy balance algorithm for land (SEBAL): 1. Formulation, Journal of Hydrology, 212-213(0), 198-212.

Bastiaanssen, W. G. M., Pelgrum, H., Wang, J., Ma, Y., Moreno, J. F., Roerink, G. J. and van der Wal, T., 1998. A Remote Sensing Surface Energy Balance Algorithm for Land (SEBAL) Part 2: Validation, Journal of Hydrology, 212-213(0), 213-229.

Bastiaanssen, W. G. M., 2000. SEBAL-Based Sensible And Latent Heat Fluxes In The Irrigated Gediz Basin, Turkey, Journal of Hydrology, 229(1-2), 87-100.

Singh, R. K., Irmak, A., Irmak, S., and Martin, D. L., 2008. Application of SEBAL Model for Mapping Evapotranspiration and Estimating Surface Energy Fluxes in South-Central Nebraska, Journal of Irrigation and Drainage Engineering, 134(3), 273-285.

Van De Griend, A. A., and Owe M., 1993. On The Relationship Between Thermal Emissivity And The Normalized Difference Vegetation Index For Natural Surfaces, International Journal of Remote Sensing, 14(6), 1119-1131. 